RERAATE DIE MLALIES

Campinas-SP, v. 38, n. 1, pp. 10-41, jan./jun. 2018

\title{
O ATLÂNTICO NEGRO ENCONTRA O OCEANO ÍNDICO: FORJANDO NOVOS PARADIGMAS DO TRANSNACIONALISMO PARA O SUL GLOBAL - PERSPECTIVAS LITERÁRIAS E CULTURAIS ${ }^{1}$
}

\author{
Isabel Hofmeyr ${ }^{2}$
}

\begin{abstract}
Resumo: Com a recente virada transnacional nas ciências humanas e sociais, as questões relacionadas ao translocalismo passaram a dominar a agenda acadêmica. Os estudos da África Austral orientados por perspetivas transnacionais basearam-se, geralmente, no modelo do Atlântico negro. Este artigo defende que é preciso complementar essa perspectiva com um engajamento sistemático com o Oceano Índico. O artigo descreve as principais tradições historiográficas associadas ao Oceano Índico, para realçar o modo como esses temas desafiam os pressupostos teorizados anteriormente com base no modelo do Atlântico negro. Na parte final do artigo, defende-se que a inclusão do Oceano Índico na cartografia da África do Sul ampliaria os mapas dos estudos culturais e literários desse país.
\end{abstract}

Palavras-chave: Oceano Índico; Sul Global; paradigma transnacional.

À medida que as ciências humanas e sociais tomam um rumo transnacional, o mercado acadêmico se enche cada vez mais de modelos que procuram explicar os fenômenos da globalização e do translocalismo. Quase sem exceção, essa tradição de estudos se concentrou nas relações

\footnotetext{
1 Este artigo foi originalmente apresentando como conferência plenária no evento "Forging the Local and the Global", Conferência AUETSA/ SAACLALS/ SAVAL, Universidade de Stellenbosch, 9-12 de julho de 2006, e publicado na revista Social Dynamics, v. 33, n. 2, 2007, pp. 3-32, com o título: "The Black Atlantic Meets the Indian Ocean: Forging Nova Paradigms of Transnationalism for the Global South - Literary and Cultural Perspectives". A tradução e a publicação deste artigo foram autorizadas pela autora.

2 Professora de Literaturas Africanas na University of the Witwatersrand, África do Sul: isabel. Isabel.Hofmeyr@wits.ac.za
} 
transnacionais norte-sul. De fato, a própria terminologia, tal como a palavra globalização, só aparentemente neutra, parece implicar processos transnacionais que emanam do Ocidente e depois irradiam-se externamente. Mas o que é o transnacionalismo dentro do próprio sul? $\mathrm{O}$ que dizer das fontes de globalização não ocidentais, ou dos processos transnacionais que acontecem sem referência à Europa? Se explorarmos algumas estatísticas, perceberemos evidente que tais questões são de inadiável importância. O comércio entre a África do Sul e a Índia subiu de R30o milhões em 1993 para R16 bilhões em 2006. Em 2005, o comércio chinês com a África, a nível continental, atingiu \$30 bilhões. O comércio do eixo Sul-Sul está se expandindo mais rapidamente do que qualquer outro fluxo comercial no mundo - cerca de $11 \%$ ao ano.

É fundamental se envolver nos debates sobre o transnacionalismo no Sul Global a partir de várias perspectivas. Este artigo procura esboçar um possível quadro para encarar essa tarefa. Em resumo, sugere-se, literalmente, olhar para a nossa localização no sul da África - entre dois oceanos - e ver a vantagem analítica que isso pode fornecer. Colocado em termos ligeiramente diferentes: o que podemos obter se pensarmos em três contextos que se cruzam: o Atlântico negro, o Oceano Índico e a própria África? Ao investigar essas questões, o presente artigo argumenta que os estudos literários da África Austral perseguiram temas transnacionais com base no modelo do Atlântico negro. Essas abordagens produziram trabalhos de qualidade que é preciso continuar e alargar, refletindo mais sobre o Oceano Índico e as suas interseções, mas também sobre as suas diferenças em relação ao Atlântico negro.

$\mathrm{O}$ artigo divide-se em três partes. Começa com um esclarecimento historiográfico das bases e das trajetórias da investigação anglófona sobre o Atlântico negro e o Oceano Índico. Em segundo lugar, coloca as seguintes perguntas: Qual a diferença que o Oceano Índico marca? Quais questões teóricas mais amplas ele levanta? Ele altera ou relativiza algumas das categorias do Atlântico que aceitamos como "normais"? Em terceiro lugar, tenta traduzir essas categorias no campo da literatura da África Austral e demonstrar como a abordagem do Oceano Índico juntamente com o Atlântico negro produziria novas definições da literatura da África Austral. 


\section{HISTORIOGRAFIAS}

\section{O Atlântico negro}

Comecemos pela parte mais fácil da equação historiográfica, nomeadamente, o Atlântico negro. O termo é, naturalmente, tão bem conhecido que, como um famoso convidado, não requer nenhuma apresentação. Em resumo, a expressão tornou-se uma fórmula para definir a costa atlântica como local de emergência do capitalismo moderno enquanto sistema transnacional. Esse sistema de articulação, dentro e através do oceano, envolve o comércio de escravos africanos, as economias de plantação americanas e as indústrias europeias que o mesmo sistema favoreceu. A partir do século XVI em diante, os povos do Atlântico são lançados dentro do vórtice da modernidade, alguns mais violentamente do que outros (GILROY, 1993; REDIKER, 1987; LINEBAUGH; REDIKER, 200o). Na famosa frase de C.L.R. James (1992, pp. 296-297), os escravos tornam-se os primeiros indivíduos modernos.

Historiadores como Marcus Rediker (1987) e Peter Linebaugh (2000) descreveram os entrecruzamentos históricos que ligavam os portos do Atlântico, cárceres, barracões, navios e plantações, e a maneira como as ideias de liberdade e igualdade foram elaboradas por marinheiros, escravos, prostitutas, trabalhadores portuários e piratas que trabalhavam nesses locais. Baseando--se, em parte, em Rediker, Paul Gilroy (1993) aprofundou a sua análise para conceber o Atlântico como o local de uma modernidade transnacional negra, não sendo considerada africana, americana, caribenha ou britânica, mas sim, uma tradução complexa dessas várias tradições em algo novo.

O paradigma do Atlântico negro (conhecido por este termo ou não) tem encontrado aplicação nos estudos literários da África Austral. Como Laura Chrisman indicou, o paradigma instruiu o pensamento de Sol Plaatje, sendo particularmente evidente nas suas interações com W.E.B. du Bois (2003, pp. 89-106). Em Songs of Zion, uma história da Igreja Episcopal Metodista Africana na África do Sul, James Campbell demonstra como as ideias do céu foram moldadas no Atlântico negro (1995). Em The African Image, Ezekiel (Es'kia) Mphahlele descreve o papel das formações culturais negras do Atlântico na África do Sul como um "diálogo através do mar" (1974, p. 96). Tim Couzens (1982) escreveu sobre a "conexão transatlântica" e o impacto dos projetos filantrópicos de matriz americana, entre 1920 e 1930, para mitigar as franjas mais radicais das 
formações culturais negras urbanas, um tema que Bheki Peterson abordou mais recentemente em Monarchs, Missionaries and African Intellectuals (2000). O mundo da música, do estilo e da moda afro-americanos exerce uma poderosa influência, tanto que muitos trabalhos acadêmicos reconstruíram a interação entre os imaginários afro-americano e sulafricano. Pode-se pensar em Rob Nixon (1994) examinando o Harlem em "Sophiatown", ou Dorothy Driver (2001) estudando as imagens das mulheres na revista Drum, ou Michael Titlestad (2004) explorando as formas musicais transatlânticas e sua interação com a literatura.

Há, naturalmente, vozes questionando os limites do paradigma do Atlântico negro. Chrisman apontou para as generalizações produzidas por ele, uma das quais celebra todos os tipos de transnacionalismo como algo benéfico e todos os tipos de nacionalismo como algo negativo. Como indica seu trabalho sobre Plaatje e Peter Abrahams, o nacionalismo não é o oposto do transnacionalismo, e aquele pode promover o outro enquanto o transnacionalismo pode produzir as suas próprias formas de exclusão (CHRISMAN, 2005, pp. 252-271). Outra voz que questionou tal paradigma foi a de Ntongela Masilela (1996), que apontou para a ausência virtual da África na discussão de Gilroy sobre o Atlântico negro.

\section{O Oceano Índico}

Passamos agora para o Oceano Índico, um sistema cultural e econômico significativamente antigo, que de acordo com alguns relatos remonta a 5.000 anos. Sugata Bose (2005, p. 6), em seu recente livro $A$ Hundred Horizons: The Indian Ocean in an Age of Global Imperialism, caracterizou o Oceano Índico como uma "arena inter-regional", um conjunto de sistemas comerciais articulados que interligam malaios, chineses, índios, árabes e africanos. Uma arena em que Grã-Bretanha, Dinamarca, França, Alemanha, Holanda, Itália, Portugal, Espanha e EUA entraram em contato com a África, Oriente Médio e Ásia Oriental.

Antes da ascensão dos navios a vapor no Oceano Índico, o núcleo da sua rede de comércio residia nos ventos alternados da monção soprando do nordeste, entre novembro e abril, e do noroeste, entre junho e outubro. A historiografia do Oceano Índico não é tão antiga quanto esses ventos, mas tem soprado há milênios, particularmente nas línguas escritas dominantes desse oceano, nomeadamente, o árabe, o persa, o gujarati e o swahili. 
A historiografia anglófona moderna do mundo do Oceano Índico, embora de origem relativamente recente, constitui um arquivo extenso e complexo. Em primeiro lugar, houve numerosas tradições populares de representação do Oceano Índico, algumas das quais pertenciam a um tipo de orientalismo marítimo. Estas incluem relatos populares como os de Empires of the Monsoon de Richard Hall (1996) e o excelente livro Islands in a Forgotten Sea de T.V. Bulpin ([s.d.]). Outros exemplos são as aventuras de Tintim, algumas das quais se desenvolvem no Oceano Índico (HERGE, 1960), bem como inúmeras histórias de piratas, aventuras de meninos e contos de heroísmo.

Quanto às análises mais especificamente acadêmicas, o Oceano Índico foi contemplado a partir de uma variedade de pontos de vista. Há, naturalmente, um corpus volumoso de estudos dedicados às diferentes regiões geográficas das margens do Oceano Índico (Moçambique, a Costa Swahili, o Chifre de África etc.), que geralmente se enquadram sob as várias categorias de estudos de área que compõem o mundo do Oceano Índico (IOW): África, Oriente Médio, Sul da Âsia, Sudeste Asiático e Austrália. Entretanto, nossa preocupação é algo diferente e envolve as tradições de estudos que procuraram entender o Oceano Índico como uma arena de entrecruzamentos (KEARNEY, 2004; McPHERSON, 1993; PEARSON, 2003; TOUSSAINT, 1966; VERGES, 2003).

Um dos focos centrais nesses trabalhos foi a ênfase nos mecanismos, escopo e escala do comércio de longa distância entre as principais cidades portuárias do IOW, e além delas. A natureza não violenta do comércio foi um dos aspectos enfatizados nesses trabalhos. Amitav Ghosh, em seu notável livro de viagem/história/memórias, In an Antique Land (1992), explorou o comércio pacífico de longa distância do Oceano Índico para fazer um contraste com o mundo contemporâneo, dividido em nações militarizadas. Engseng Ho apresenta ideias semelhantes em seu trabalho sobre a diáspora Hadrami no Oceano Índico, uma antiga diáspora de um povo que saiu do sul do Iémen, alcançando o âmago do Oceano Índico, sem qualquer auxílio de um estado armado:

No Oceano Índico, os portugueses, holandeses e ingleses eram estranhos novos comerciantes que trouxeram o seu estado com eles. Eles criaram postos militarizados de comércio no Oceano Índico, ao exemplo dos precedentes venezianos e genoveses no Mediterrâneo, e costumavam fazer negócios através do uso de armas. O povo Hadramis e outros povos não-europeus - como os Gujaratis, Bohras, Chettiars, Buginese e Malaios - não tinham esse costume. (HO, 2006, p. xxi) 
Nas palavras de Ho (2006, p. xxi), "os não-europeus começaram a ter com os locais relações mais íntimas, estreitas e prolongadas do que os europeus conseguiam conceber".

Conforme Bose ressalta, embora exista uma vasta tradição de estudos sobre o passado distante do mundo do Oceano Índico, há comparativamente menos sobre os séculos XIX eXX. Uma notável exceção foi o trabalho de Mark Ravinder Frost (2002), que começou a delinear uma esfera pública do Oceano Índico distinta, que floresceu desde a década de 1880 até a de 1920. Sediada nas cidades portuárias do Oceano Índico e sustentada pelos grupos de intelectuais das diásporas que se cruzaram, essa esfera pública enraizou-se em movimentos pan-religiosos, sejam estes budistas, muçulmanos ou hindus. Como observa Frost (2002, p. 937), os grupos de intelectuais diaspóricos das cidades portuárias compartilhavam "preocupações semelhantes para reformar e supervisionar as campanhas paralelas de reavivamento religioso, melhoria da educação e mudança constitucional". Esses circuitos intelectuais produziram um mundo de universalismos transversais e contestadores, concebendo o colonialismo menos como um encontro entre o local e o global, do que como uma disputa entre diferentes universalismos.

O Oceano Índico fornece uma arena em que tais universalismos do sul ficam visíveis. Quais foram alguns desses universalismos? Outra maneira de endereçar essa questão é a seguinte: Quais são os temas unificadores do IOW? Dada a amplitude e profundidade dos estudos sobre o Oceano Índico, há inúmeras respostas a essa pergunta, de acordo com os modos diferentes pelos quais os estudiosos "criam", analiticamente, o Oceano. Títulos recorrentes são o comércio, o capital e o trabalho; a religião (muitas vezes ligada ao comércio); a peregrinação; as viagens; a guerra, o domínio colonial e os movimentos anticoloniais; e as cidades portuárias. Outros temas focam grupos específicos como os muçulmanos, os portugueses, o domínio britânico e assim por diante.

$\mathrm{O}$ quadro histórico que esses temas exploram é bem conhecido. Uma vez dominada pelos marinheiros, a monção permitiu a viagem em alto mar e o comércio no Oceano Índico. A partir do século VIII, essas redes comerciais foram consolidadas e promovidas pela disseminação do Islã no Oceano Índico, o que ajudou a unir uma série de cidades portuárias cosmopolitas: Kilwa, Mombasa, Malindi, Mogadishu, Leddah, Aden, Muscat, Cambay, Calicut e assim por diante. O Islamismo forneceu o idioma dominante da vida pública na maioria das cidades litorâneas e 
promoveu novas categorias de viajantes, principalmente, peregrinos, administradores e estudiosos que passaram a usar o árabe como língua internacional. O Islão proporcionou uma "gramática" no Oceano Índico, e uma forma de universalismo que facilitou o intercâmbio e a mobilidade porvastasáreas (KEARNEY, 2004; RISSO, 1995; FATTAH, 2002; FAWAZ; BAYLY, 2002).

No final do século XV, os portugueses chegaram ao Oceano Índico, seguidos pelos holandeses, dinamarqueses, franceses, britânicos, alemães e, posteriormente, italianos. Com base em alguns relatos, a chegada do poder militar europeu marcou uma grande divisão na história do Oceano Îndico, com um período aparentemente pacífico de comércio desarmado, seguido da crescente militarização e do conflito precipitado pela intrusão dos europeus. Empires of the Monsoon, de Hall, exemplifica essa narrativa; com o subtítulo A History of the Indian Ocean and its Invaders, as duas primeiras partes do livro são "A World Apart" e "The Cannons of Christendom" (1996).

Esse modelo de inocência pré-lapsariana do Oceano Índico, desintegrado pelos europeus, foi questionado. Ashin Das Gupta (2004) demonstrou que o declínio do comércio do Oceano Índico tem menos a ver com o poder europeu do que com as circunstâncias internas da Índia. Olhando para o comércio da pimenta, Gupta narra como a luta pelo controle dessas transações em Malabar e Mysore no início dos anos 1700 levou ao seu colapso. Como todos os outros comerciantes, os europeus, até pelo menos o século XVIII, tiveram que se acomodar às condições locais, convenções e redes comerciais de crédito. Eles faziam parte da ordem comercial asiática. Somente com a ascensão dos navios britânicos a vapor, do controle marítimo, dos exércitos permanentes, do Canal de Suez, da telegrafia elétrica e uma variedade de outros aparelhos tecnológicos, o Oceano Índico começou a se assemelhar a um "British Lake" (BOSE, 2005, p. 274). No entanto, Rajat Kanta Ray demonstrou que a ascensão do poder colonial não significou o fim das extensas redes de comércio e crédito indianas e chinesas. Sob o radar da autoridade imperial europeia, as redes de crédito e comércio Gujarati, Sind e chinesas continuaram a operar nessas áreas - África Oriental, Muscat e Sudeste Asiático - que, equivocadamente, nunca estiveram sob a influência de um poder colonial, ou onde o controle colonial demorou para chegar, ou onde "grandes banqueiros ocidentais não poderiam ou não queriam ir" (RAY, 1995, p. 552). Dentro desse quadro mais amplo, vamos nos concentrar em 
dois temas de grande relevância no plano literário: "Ilhas" e "Pessoas e passagens".

\section{Ilhas}

Um tema amplo nos Estudos do Oceano Índico foi a ideia de ilha como resumo das experiências de escravidão e trabalho forçado no Oceano Índico. Muitos estudos buscaram compreender as ilhas como espaços crioulos, focando a história das pessoas, sem referência à nação: uma espécie de modelo ultracaribenho de tradições europeias, africanas e asiáticas, violentamente agrupadas. Vários estudiosos usaram as experiências insulares para criar conceitos a fim de pensar o mundo do Oceano Î́ndico, em geral. Algumas dessas ideias - como a créolité ou o termo antillanité, de Edouard Glissant -, embora usadas para incluir as experiências insulares do Oceano Índico, são de origem caribenha (CARTER; TORABULLY, 2002).

Outras ideias procuraram ser mais específicas ao Oceano Índico, como o conceito Mauriciano de Indienoceanisme, ou o de coolitude, formulados pelo poeta Mauriciano Khal Torabully e a historiadora Marina Carter (2002). A coolitude se forma em relação à "negritude"; mas reconhece que a "negritude" não leva em consideração a complexidade das sociedades pós-abolicionistas, particularmente, porque estas se desenvolveram no Caribe e no Oceano Índico. A coolitude busca revalorizar o termo coolie, ${ }^{3}$ transformando uma ofensa numa forma de empoderamento. Nas palavras da crítica belga Veronique Bragard (apud CARTER; TORABULLY, 2002, p. 15), o tema central da coolitude é a viagem por mar, que se torna um local de trauma e de perda, mas também uma "metonímia de encontros culturais". Ela continua:

\footnotetext{
A travessia de Kala Pani ["água negra"] constitui o primeiro movimento de uma série de situações abusivas e culturalmente sufocantes. Tornando a travessia o tópico central, a coolitude evita qualquer essencialismo e conexão com uma Mãe Îndia idealizada, que é claramente deixada para trás. Ela revela a história do Coolie que naufragou ("foi apagada") no oceano de um discurso histórico feito no ocidente, assim como em um mundo de publicação e crítica. (BRAGARD apud CARTER; TORABULLY, 2002, p. 15)
}

3 NT: Termo pejorativo utilizado pelos europeus para designar os trabalhadores contratados de origem asiática, maioritariamente indiana. 
Nas palavras de Torabully (2002, p. 150), “a coolitude propõe um encontro, uma troca de histórias, de poesia ou visões do mundo, entre as pessoas de ascendência africana e indiana, sem excluir outras origens". O tópico central na poesia de Torabully é o que ele chama de "Book of the Voyage" (p. 15), uma maneira de tornar legíveis as experiências apagadas de trabalho forçado.

\section{Pessoas e passagens}

Uma segunda abordagem para explorar a unidade do Oceano Índico é focar as pessoas que atravessaram as suas águas. Esse tema procura investigar o movimento de escravos, trabalhadores contratados, colonos e imigrantes nos últimos três séculos. Serão examinados três grupos: escravos, trabalhadores contratados e migrantes livres.

\section{Escravidão no Oceano Índico}

Geralmente, os trabalhos acadêmicos sobre o tráfico de escravos no Oceano Índico buscam estabelecer distinções em relação ao comércio no Atlântico (CAMPBELL, 2004b; SEGAL, 2001). Ao longo de 4.000 anos, o Oceano Índico conheceu diversas formas de comércio de escravos. A ascensão do Islamismo e a expansão comercial ocasionaram um aumento na escala do comércio, assim como o crescimento das cidades portuárias e a necessidade de mão de obra barata. O aumento das economias de plantação nos séculos XVIII e XIX, em Maurício e Zanzibar, estimulou ainda mais o comércio, juntamente com o envolvimento Europeu a partir do século XVI. O comércio era multidirecional, com pessoas que se deslocavam dentro da África, da África ao Oriente Médio e, a partir do século XVIII em diante, para as ilhas, a Índia e as Américas. Os escravos indianos foram enviados, por navios, à Indonésia, às ilhas, à Cidade do Cabo e ao Oriente Médio, enquanto os indonésios foram transferidos para o Sudeste Asiático e a Cidade do Cabo; e os africanos foram transportados do litoral moçambicano para a Cidade do Cabo e as Ilhas do Oceano Índico (CAMPBELL, 2004b).

As diferenças em relação ao modelo Atlântico foram resumidas por Gwyn Campbell: o comércio no Oceano Índico era, em grande parte, feminino, não masculino; envolveu predominantemente escravos domésticos, em vez de trabalhadores de plantação; os limites entre escravos e indivíduos livres eram muito mais desfocados do que no 
Atlântico; e, além disso, a associação de raça e escravidão não existiu em qualquer forma registrada (CAMPBELL, 2004a).

\section{Contrato de trabalho forçado}

O Oceano Índico tornou-se um dos principais locais para a implantação de mão de obra contratada. Como a escravidão foi proibida no Império Britânico em 1834, os proprietários de plantações sofreram uma crise laboral ameaçadora, que foi enfrentada através do amplo recurso a trabalhadores indianos contratados. Esse movimento maciço de mão de obra contratada gerou a sua própria historiografia, que procurou distinguir os contratos de trabalho forçado tanto da escravidão, quanto da imigração europeia "livre" (TINKER, 1974). Essas categorias também passaram a ser racializadas (CARTER, 1996; NORTHRUP, 1995). Na imaginação popular, os escravos são africanos, os trabalhadores contratados são indianos, enquanto que os colonos são brancos.

Esse imaginário popular é, naturalmente, incorreto. Havia escravos indianos, assim como houve um pequeno número de trabalhadores contratados africanos e europeus (NORTHRUP, 1995). Do mesmo modo, como observou um historiador do trabalho, "a maioria dos cinquenta milhões de emigrantes europeus eram recrutas trabalhistas [...] os trabalhadores contratados se tornaram pequenos agricultores e arrendatários nas colônias de açúcar” (apud CARTER, 1996, p. 3). No Oceano Índico, a distinção entre trabalhador contratado e colono é, portanto, obscura, assim como nem sempre foi visível aquela entre o escravo e o indivíduo livre.

A tendência atual é ver essas distinções racializadas como resultantes dos discursos coloniais e dos modos de governo. O processo de mover, categorizar, controlar e administrar o trabalho se tornou um local para construir ideias de raça e para formular ideias de populações biopolíticas. O trabalho de Jonathan Klaaren (2004) demonstrou que as ideias da cidadania sul-africana surgiram em relação às leis de imigração e às práticas de administração formuladas para os "asiáticos" (nomeadamente trabalhadores contratados indianos e chineses). Na década de 1920, um cidadão sul-africano foi inicialmente definido como alguém que não era imigrante ilegal. Como Klaaren demonstra, essa visão xenófoba da cidadania tem ressonâncias interessantes com a nossa situação contemporânea. 
A nova historiografia trabalhista no Oceano Índico, enquanto está atenta às diferentes categorias de trabalho, também aponta para o valor de agrupar analiticamente os diferentes tipos de trabalho no - e além do - Oceano Índico (CARTER, 1996). Esse Oceano pode, portanto, ser visto como uma arena de experiência colonial no controle do trabalho sem liberdade, seja este por meio de escravo, condenado, contratado ou, aparentemente, por migração voluntária "livre". Números significativos de condenados, por exemplo, foram movidos pelo Oceano Índico, alguns para as Ilhas Andaman e a Ilha Robben da Índia (ANDERSON, 2005). Igualmente, a administração do trabalho por contrato tornou-se um importante local para experimentos de governança colonial. Maurício, por exemplo, foi o primeiro lugar no mundo onde a fotografia foi usada para fins de governo (BRÉVILLE, 1999, p. 399).

O mundo dos lascars - marinheiros africanos e asiáticos -, que surgiu como uma categoria específica de trabalhadores marítimos, sob o domínio britânico, também esteve vinculado a essa forma de controle do trabalho (BALACHANDRAN, 2003; EWALD, 2000). O Império tinha extensas redes de comunicação e transporte e, portanto, uma demanda insaciável de mão de obra barata para construir portos e navios a vapor. O grupo que preencheu essas funções era composto de marinheiros africanos e asiáticos, sujeitos a contratos de trabalho específicos e que fixaram seus salários na base de um terço a um quinto do salário dos marinheiros europeus. Eles também assinaram contratos que os impediam de se instalar na Grã-Bretanha, de modo que a maioria dos lascars passaram a ser vistos como mão de obra contratada de migrantes de longa distância.

\section{Migrantes livres}

O Oceano Índico era uma zona para muitos itinerantes: peregrinos, administradores, soldados, marinheiros, comerciantes e mercadores. Os exemplos mais conhecidos dessa migração voluntária foram os migrantes sul-asiáticos que se mudaram para o Leste e o Sul da África (BHAN; BRAIN, 1990; GREGORY, 1971). A presença de mercadores de Gujarati na África Oriental remonta a muitos séculos. Esses comerciantes também tinham redes de comércio que se estendiam para o interior do continente (ALPERS, 1976). Com o advento dos contratos de trabalho forçado a fim de construir as ferrovias do leste africano, a população de comerciantes aumentou. Devido ao atraso na entrada do Império na África Oriental, no final do século XIX, o Reino Unido explorou os vínculos e caminhos estabelecidos pelos comerciantes (GREGORY, 1971). Na África também 
havia migrações livres para fora do continente. A partir do século XIII em diante, africanos, por exemplo, migravam para outras partes do Oceano Índico, não apenas como escravos, mas também como "policiais, comerciantes, burocratas, clérigos, guarda-costas, concubinas, servos, soldados e marinheiros" (JAYASURIYAE PANKHURST, 2003, p. 7; ALI, 1995).

Para resumir, então: se o Oceano Índico opera ou operou como uma rede, sua unidade residia em uma miríade de fatores: comércio, capital, religião, guerra, peregrinação, portos, navios, escravos, trabalhadores contratados, clérigos, marinheiros, credores e mercadorias (BOSE- 2005, p. 12 - observa que, entre os séculos XVI e XIX, a maioria dos habitantes do Oceano Índico usava algodão indiano proveniente de Gujarat, Coromandel ou Bengal).

\section{O OCEANO ÍNDICO: E DAÎ?}

Vamos voltar então à pergunta inicial: Que diferença o Oceano Índico pode fazer? Primeiro, no entanto, uma advertência: ao generalizarmos sobre o Oceano Índico corremos o risco de estabelecermos uma dicotomia rígida entre ele e o Oceano Atlântico. Em tal contraste, o Índico parece pré-moderno, uma zona de Islã atemporal contra o modernismo do Atlântico capitalista; em tais análises, o Oceano Índico surge como a zona da inocência perdida, de certa forma, como o continente místico perdido, Lemúria, que, de acordo com alguns relatos, estava originalmente no sul da Índia, antes de afundar sem deixar vestígios.

No seu trabalho sobre a Lemúria, Sumathi Ramaswamy analisa a história do continente perdido como uma ideia da ciência europeia, depois do pensamento colonial sobre a Índia, por fim, do nacionalismo Tamil (em que Lemúria se torna a pátria perdida do Tamil) (RAMASWAMY, 1999; 2002). Em resumo, a Lemúria é carregada de nostalgia de uma pré-modernidade imaculada, um dos modelos produzidos por concepções românticas do Oceano Índico. Em vez disso, precisamos pensar o Î́ndico como o local por excelência das "modernidades alternativas"; formações da modernidade que tomaram forma em um arquivo de tradições sociais e intelectuais profundas e articuladas.

\section{QUEM É UM ESCRAVO?}


Como a discussão de Campbell (2004a; 2004b) já indicou, o Oceano Índico marca uma diferença na questão de "quem é um escravo" ou, colocado em termos diferentes, a distinção entre relações de escravidão e de liberdade. A esse respeito, o modelo Atlântico se tornou invisivelmente normativo. $\mathrm{O}$ estatuto de escravo e livre é claramente demarcado e, além disso, racializado. Essa rigidez se dá em vários domínios. Em muita teorização política, as noções de subjetividade, soberania, autonomia e liberdade tendem a regular a ideia de que a escravidão e a liberdade são estados perfeitamente separáveis. Essa distinção absoluta também é evidente nas tradições de pensamento anticolonial e nos paradigmas hidráulicos de dominação e resistência a que estes dão origem. Em tais análises, os domínios de governante e governado, opressor e oprimido são aparentemente distintos e legíveis.

A escravidão no Oceano Índico era mais complexa: a linha entre escravo e livre estava constantemente se deslocando e mudando. Como Campbell argumenta (2004a), a maioria dos escravos no Oceano Índico geralmente não estavam localizados na estrutura de plantação, mas integrados nas famílias. Consequentemente, houve maiores possibilidades de mobilidade ou alforria. As possibilidades de mobilidade ou alforria eram maiores. A servidão por dívida ou a penhora de um membro da linhagem/ família eram também estratégias típicas em tempos de catástrofes, tais como as secas e a fome. A esperança, no entanto, era que essas situações não fossem permanentes.

Os significados de liberdade e escravidão, então, são complexos e variados. É importante lembrar isso em um contexto pós-apartheid, em que o glamour das narrativas de dominação e resistência se desgastou. $\mathrm{Na}$ verdade, tais narrativas estão agora sendo reabilitadas como parte de uma história oficial do Estado. Como os teóricos políticos mostraram em outros lugares do continente, os nossos entendimentos sobre poder precisam ser mais complexos do que aquilo que esses binarismos implicam. O trabalho de Achille Mbembe demonstrou a íntima convivência de governantes e governados (2001). Da mesma forma, outros teóricos políticos, como Jean-François Bayart (1993), Patrick Chabal e Jean-Pascal Daloz (1999), criticaram as visões excessivamente dicotómicas da sociedade africana, dividida entre popular e elite, elevado e inferior. Seja qual for a assimetria de poder entre esses grupos, eles ainda estão ligados por redes populistas de clientelismo e dependência. 
Entender o discurso político e a ação, então, significa compreender um complexo arquivo pré-colonial, colonial e pós-colonial no qual as versões da modernidade são negociadas em um conjunto de linguagens sempre em mudança, em torno da "tradição". Uma área da África que oferece uma fonte rica para a compreensão dessas interações é a Costa Swahili. Ali, como Jonathan Glassman (1994) demonstrou brilhantemente, uma variedade de círculos eleitorais - sociedades do interior, famílias patrícias do Swahili islâmico, uma multidão urbana de escravos e plebeus, todos sob o domínio dos sultões de Omani - formaram uma série de culturas públicas cosmopolitas que giravam em torno da política de reputação e do terreno disputado de reciprocidade e exibição pública. Dentro dessas exibições cerimoniais, o próprio poder - por exemplo, o patriarcado - não era diretamente desafiado; em vez disso, seus significados, direitos e suas obrigações foram contestados. A intervenção colonial no Oceano Índico foi um participante tardio nesse mundo complexo e teve que se acomodar aos contornos esculpidos em muitos séculos de interação.

Um romance que explora esse terreno, soberbamente, é Paradise de Abdulrazak Gurnah (1994). Situado na véspera da Primeira Guerra Mundial, na costa Swahili, o romance examina a trajetória de Yusuf, penhada por seu pai a um rico parente comerciante para compensar a dívida do genitor. O romance examina a complexa interação entre as formas de opressão africanas, indianas, árabes, alemãs e britânicas. O que a escravidão significa nesse contexto? O que significa liberdade? O que é ação? Tais romances, embora não estritamente falando da África Austral, são importantes porque começam a abrir as complexidades do Oceano Índico e podem nos ajudar a entender as formas de modernidade que ele produz. Essa é uma tarefa que outros estão começando a assumir. Leila Tarazi Fawaz e Christopher Alan Bayly (2002), em Modernity and Culture: From the Mediterranean to the Indian Ocean, começaram a examinar as formas de modernidade cosmopolita que emergiram através da interação do Oriente Médio com as Sociedades Asiáticas do Sul e como estas adaptaram e escreveram formas de modernidade europeia, escolhendo temas como a impressão, o islamismo urbano e a linguagem universal do islamismo, em geral.

\section{QUEM É UM COLONO?}


Se nos for pedido para repensar o significado de escravo, também seremos convidados a reconsiderar a ideia de quem é entendido coomo colono. Como indicado acima, a historiografia mais antiga definiu esse termo racialmente. Geralmente, os colonos eram aqueles que vinham do norte, considerados livres e direcionados tautologicamente para as colônias de povoamento. Os trabalhadores contratados eram do sul, não eram livres e se dirigiam às colônias de açúcar. No entanto, esses trabalhadores, geralmente, tornavam-se colonos e tentavam se inserir nos discursos de domínio colonial. Por exemplo, 1960 marcou o centenário da chegada do primeiro trabalhador indiano contratado em Natal. As celebrações para esse evento se deram sob o título de "Os colonos de 1860" (PATHER, 1960), retomando (e respondendo a) a ideia de "Os colonos de 1820 ", o mito de origem construído por intelectuais brancos de língua inglesa em resposta ao crescente nacionalismo africano. A ideia dos colonos indianos foi também bem desenvolvida em relação à África Oriental, em que os indianos foram retratados como os verdadeiros "pioneiros" que estavam "abrindo" o interior da África. M.K. Gandhi frequentemente escreveu sobre esses colonizadores, a quem ele caracterizava como sendo melhores do que os ingleses, uma vez que não bebiam e não tinham a Bíblia (GANDHI, 1919; ANON., 1921; TADVALKAR, 1919).

Essas narrativas levantam questões de grandealcance sobre os colonos e sobre o Império. Quem foi um colono? O que era o Imperialismo? A quem pertencia o Império? Um romance que dramatiza essas questões é o clássico infanto-juvenil gujarati Dariyalal (Lord of the Seas) por Gunvantrai Acharya, resumido e traduzido por Kamal Sanyal (2000). A história se desenrola em um assentamento de Gujarati em Zanzibar, no final do século XVIII e início do século XIX, e se concentra em Ram, um implacável comerciante de escravos. À medida que a narrativa começa, ele muda radicalmente sua opinião sobre a escravidão e, no final da história, consegue persuadir os Zanzibari Gujaratis a desistir da escravidão e mudar para a produção de cravo-de-seda. Nessa narrativa está presente um gênero de aventura colonial, em que Ram salva John Dunkirk de tribos canibais (Dunkirk é um membro fictício do partido Mungo Park que, de alguma forma, abriu caminho do oeste para o leste da África). Jogado nessa mistura está o inevitável mito de Ram e Sita (protagonistas românticos do Ramayana, poema épico hindu escrito em sânscrito) e uma agenda reformista hindu com os "bons mocinhos" na casta opositora. 
Visto da perspectiva do sul da África, o romance de Acharya nos pede para recontextualizar uma série de gêneros: a história do colono, a narrativa antiescravidão, o conto de aventura colonial e o gênero de romance. Um conjunto similar de realinhamentos emerge se observarmos outro conjunto de migrações do Oceano Índico, nomeadamente, aquelas associadas aos goeses. Num recente colóquio realizado na Universidade de Witwatersrand sobre "África do Sul-Îndia: Re-imaginando as Disciplinas", Rochelle Pinto e Pamila Gupta apresentaram trabalhos sobre esse tema. Normalmente assimiladas, não sem dificuldades, dentro das histórias indianas ou indo-portuguesas, a história dos goeses itinerantes oferece uma nova perspetiva sobre os velhos temas do império e da nação. Pinto (2006) demonstra como os goeses dos séculos XVIII e XIX, um grupo periférico em um império periférico, exploravam a fluidez e a ambiguidade das hierarquias raciais do Império, às vezes criando as suas reivindicações de "Portugalidade", outras vezes, apagando suas associações próximas com os africanos. Os goeses tentaram se inserir em narrativas e arenas coloniais moldadas por discursos raciais interativos, criados pelas práticas coloniais francesas, britânicas e, em menor escala, portuguesas. Gupta (2006) examina a comunidade de goeses que imigrou para Maputo depois de 1961 (quando a Índia retomou Goa dos portugueses) e permaneceu ali depois da independência moçambicana, em 1975. Ela procura usar a natureza itinerante desse grupo para investigar a historiografia existente sobre a descolonização, que geralmente vê o processo como algo ainda não completo, como algo que ainda está a se desenrolar em um quadro evolutivo. Em vez disso, Gupta explora a "descolonização" como um evento justificado por si próprio e como um processo histórico global com múltiplos efeitos, incluindo a rapidez de novas migrações.

Via Moçambique, evidentemente, a questão das narrativas dos goeses faz entrada na literatura do Sul da África. Vou dar apenas um exemplo: o conto profundamente cômico de Mia Couto (1986), "Como Ascolino do Perpétuo Socorro perdeu a sua cônjuge”, na coleção Vozes Anoitecidas. A história é uma alegoria do domínio colonial e da descolonização em Moçambique, narrada através de um protagonista goês que se desloca por várias identidades. Quando está sóbrio, ele vê a si mesmo como um respeitável indo-português, quando está embriagado ele deseja formar uma aliança com moçambicanos africanos comuns, tudo isso alegando estar apaixonado pela sua esposa, a quem nunca vemos e que é equivalente a Portugal, a Mãe-pátria. A história abre novos caminhos ao 
narrar o domínio colonial como comédia. Ao explorar as possibilidades da marginalidade do Oceano Índico, a história aponta o caminho para um novo conjunto de imaginações literárias.

Uma consideração do Oceano Índico abre assim novas vias para pensar a "raça": um exemplo óbvio aqui seria a maneira pela qual se dá a branquitude no Império, sendo dois pontos importantes a África do Sul e a Austrália. Como Jon Hyslop (1999) demonstrou, ideias de trabalhismo branco foram formuladas em uma ampla variedade de colônias de povoamento branco. Essas ideias de "brancura" também foram afiadas na marinha mercante, um local em que os marinheiros eram cada vez mais racializados. Como nas minas sul-africanas, os trabalhos qualificados eram feitos por brancos, enquanto que aqueles mais fisicamente exigentes, eram feitos por marinheiros africanos e asiáticos, os já citados lascars. A crescente popularidade da teosofia - através de figuras como Annie Besant, Madame Blavatsky e o Coronel Olcott (VAN DER VEER, 2001, pp. 55-82; VISWANATHAN, 1998, pp. 177-207) - também abriu novas vias para repensar a "branquitude" no IOW. Havia espiritualistas entusiastas na África do Sul, um dos quais era o Sr. G. Williams, um grande fã de Parmanand. Williams (apud KHURSAND, 1982, p. xxi) escreveu para Parmanand na Índia dizendo: "Esta forma europeia que eu assumi neste nascimento foi uma fonte de dor e de muitas dificuldades para mim”.

\section{DIÁSPORA}

Outro termo que o Oceano Índico exige que repensemos éa “diáspora”. A palavra tornou-se central para o léxico pós-colonial e, no seu sentido mais amplo, é usada para descrever quase qualquer tipo de movimento. $\mathrm{O}$ extenso uso acadêmico da palavra tende a ser aplicado de forma mais consistente após o movimento da década de 1960, do sul para o norte, ocasionado por mudanças nos EUA e nas leis de emigração europeia destinadas a atrair mais migrantes da classe média. Em comparação com o movimento do trabalho contratado do século XIX, esse movimento do século XX envolveu pessoas de uma classe social superior e, portanto, atraiu mais atenção. Boa parte do debate contemporâneo sobre a diáspora, e o vocabulário pós-colonial a ela associado, de hibridez e hifenização, é implicitamente teorizado com base neste último grupo. O termo, no entanto, aplica-se com dificuldade ao Oceano Índico. Em primeiro lugar, o Índico tem sido o lar de diásporas fracassadas, principalmente de pessoas 
que se movem, mas não iniciam projetos de memória cultural e construção de pátrias. Um exemplo notável é o movimento de escravos africanos e migrantes livres para o Oriente Médio e Sul da Ásia (JAYASURIYA; PANKHURST, 2003). Essas comunidades, geralmente, mantiveram pouca lembrança da África ou indicaram pouca vontade de retornar.

Outro uso comum do termo é relacionado ao movimento dos indianos para a África. Esse tópico faz mais sentido, porém - conforme o trabalho de Patrick Eisenlohr sobre Maurício indica -, o termo "diáspora", como se desenrola em partes do Oceano Índico, requer revisão. Eisenlohr (2006, pp. 227-265) observa que as análises da diáspora indiana passaram por três estágios. Inicialmente, a partir da década de 1960, as análises dos indianos que migraram focaram questões de sobrevivência e traços: De que modo a "cultura indiana", geralmente entendida como casta, e a família conjunta sobreviveram ou mudaram à medida que se deslocavam para novos locais? Uma segunda onda de análises inclinou-se mais a enfatizar a invenção das comunidades da diáspora, ao invés de vê-las como "transplantes" que voltaram a olhar automaticamente para uma pátria "originária”. Esse conjunto de abordagens se concentrou mais em como certos temas como pureza e poluição - foram inventados e reinventados. Uma terceira orientação foi examinar as comunidades da diáspora como construções coloniais e pós-coloniais: "destacar os aspectos coloniais da migração ajudou a explicar quer a formação das comunidades indianas no exterior fora dos grupos altamente heterogêneos de imigrantes, quer as profundas transformações a que eles foram submetidos nos contextos do império e do trabalho forçado" (EISENLOHR, 2006, p. 233). Eisenlohr resume: "os estudos existentes mostraram que as comunidades da diáspora indiana não podem, de modo algum, ser consideradas extensões da Índia” (p. 233).

Atualmente, há excelentes trabalhos sobre a ficção indiana na África do Sul e África Oriental por, entre outros, Devarakshanam Govinden (prestes a ser publicado), Ronit Fainman-Frenkel (2004), Rajendra Chetty (2002) e Dan Ojwang (2004). Esse arquivo narrativo já iluminou a invenção da diáspora e continuará a fazê-lo. O presente trabalho, por sua vez, faz parte de uma crescente reavaliação de como escrever e pensar sobre a história das comunidades contratadas. Em termos brutos, essa história foi até recentemente uma história de movimento unidirecional que examina a migração de trabalhadores, com contratos forçados, da Índia para várias partes do mundo. A questão do que significa essa migração para a Îndia ou o que as formações intelectuais na diáspora significam para 
os desenvolvimentos no local de origem, foram raramente exploradas. A "nova" diáspora pós-196o da Índia para o norte, naturalmente, atraiu muito mais atenção. Como Uma Dhupelia-Mesthrie observou em um discurso-chave no encontro "África do Sul-Índia: Re-imaginando as Disciplinas" (Universidade de Witwatersrand, 2006), a "antiga” diáspora contratada do sul, no entanto, é pouco estudada na própria Índia, sendo consignada aos estudiosos das diásporas periféricas.

Como ela mostrou, essa situação está começando a mudar, principalmente com o trabalho de John Kelly (1991) sobre Fiji e de Tejaswini Niranjana (1999) sobre Trinidad. Ambos os textos abordam temas de gênero e diáspora. $\mathrm{O}$ trabalho de Niranjana sobre a diáspora de Trinidad e sua sobreposição mútua com o nacionalismo indiano mostra como a Índia e suas diásporas contratadas se marcam reciprocamente. Ela demonstra como as mulheres indianas de alta casta e classe média no discurso nacionalista dependem da negação das mulheres de castas inferiores, que foram enviadas de forma real ou imaginada para locais distantes de trabalho contratado. As mulheres de castas inferiores na diáspora foram retratadas como corrompidas pelo sistema de contratos forçados ou, como incorporando o tropo da virtude feminina hindu ameaçada, um tema que Kelly desenvolve extensamente. Esse tropo foi propagado energicamente na Índia e surgiu para unir uma série de círculos eleitorais anticoloniais em uma campanha destinada a exigir o fim dos contratos forçados. O importante trabalho de Niranjana destaca o tema da modernidade negada. Os que estão na diáspora embarcam em seus próprios projetos modernistas, mudando de ideia sobre as castas, o gênero e a religião. Muitas vezes, essas formas de modernidade têm ecos na Índia, mas, geralmente, em maneiras que retratam a casta inferior e a modernidade da classe de comunidades contratadas como indesejáveis.

\section{NOVOS CIRCUITOS LITERÁRIOS}

Esses movimentos de ideias de um lado para o outro no Oceano Índico nos ajudam a ver novos circuitos literários. Um exemplo é extraído da revista Modern Review, periódico sediado em Calcutá, fundado em 1907 por Ramananda Chatterjee. A revista era um importante fórum nacionalista e, como muitos empreendimentos nacionalistas, tinha uma forteagenda reformista, particularmente no que diz respeitoao hinduísmo, que os nacionalistas procuravam "modernizar" e "racionalizar". A revista 
realizava relatórios extensos sobre a diáspora contratada eapresentava uma coluna regular sobre os "Indianos no Exterior". Esses relatórios fornecem uma janela para a compreensão de como os debates organizados na diáspora foram tecidos nas agendas nacionalistas internas. Por exemplo, uma questão crítica no debate reformista/nacionalista dizia respeito às castas, e a revista referiu muitas vezes que as comunidades da diáspora estavam mudando as castas para melhor. Deve-se dizer que elas eram comunidades de elite; quando as comunidades contratadas abandonaram as castas, isso foi visto invariavelmente mais como perda que como um ganho (HOFMEYR, 2006).

Figuras de destaque também intervieram em debates na diáspora. Em 1928, por exemplo, Rabindranath Tagore entrou em um debate em Fort Hare College, a única universidade aberta aos sul-africanos negros na época. Um pequeno número de indianos frequentavam há muito tempo Fort Hare. Como parte do Acordo de Cape Town de 1927, as comunidades indianas deveriam ter maior acesso à educação. Uma parte desse pacote era fornecer maior acesso a Fort Hare. Alguns indianos sul-africanos opuseram-se a essa tentativa de classificá-los como "nativos" e suas opiniões foram reportadas na Índia. Tagore reuniu seu magisterialismo moral e repreendeu a comunidade indiana da África do Sul, ao dizer: "O nosso único direito de estar na África do Sul é que os nativos africanos, a quem o solo pertence, desejem que estejamos lá" (ANON., 1928a, p. 356; ANON., 1928b; 1928c).

Esses tipos de diálogos e tradições textuais ainda não foram exploradas com alguma profundidade. Outro exemplo: em junho de 1928, a Modern Review publicou um artigo intitulado "África do Sul e Índia: a mensagem de Olive Schreiner" (ANDREWS, 1928, pp. 641-646). O autor do artigo era C.F. Andrews, um missionário anglicano aposentado que conheceu Olive Schreiner ao ficar algum tempo na África do Sul. Ele também se tornou um dos confidentes de Gandhi. O artigo de Andrews (1928, p. 642) resume a "Closer Union" de Schreiner e, em seguida, faz alguns paralelos com a Índia: "A Índia representa um conjunto ainda maior de raças do que a África do Sul; e a luta pela unidade racial na Índia tem muitos séculos, enquanto que na África do Sul ela apenas começou". A ideia de Olive Schreiner em Calcutá não é algo que frequentemente pensamos, mas é uma conjunção que mantém possibilidades excitantes.

Outro exemplo de uma circulação literária um tanto contra-intuitiva vem da história dos indianos sul-africanos repatriados. Como Uma 
Mesthrie (1985) demonstrou, a partir da década de 1920, o Estado sulafricano fez tentativas árduas de enviar os indianos para as suas casas, disponibilizando ofertas lucrativas em dinheiro para a repatriação. Aqueles que aceitaram tais ofertas tiveram de desistir do seu direito de retornar à África do Sul. A maioria dos repatriados teve grande dificuldade em se adequar de volta à sociedade indiana: eles já tinham perdido sua casta e alguns já não falavam nenhuma das línguas indianas. A maioria dos repatriados acabaram em comunidades de favelas, em Madras e Calcutá. Alguns tiveram vidas extraordinárias. Muni Gadu e a sua família foram repatriados e depois solicitaram permissão para retornar à África do Sul. O seu pedido foi recusado, mas a família, mesmo assim, decidiu pegar um navio com destino a Dar es Salaam, de onde andaram 2.500 milhas em direção a Natal (CHATURVE; DAYAL, 1931).

Os arquivos nacionais sul-africanos guardam muitas das cartas dos repatriados, que suplicavam para voltar ao país. Essas cartas constituem um corpus de textos do Oceano Índico ainda por estudar, que aponta para a potencial riqueza das histórias dos contratados, vistas não como uma história unidirecional, mas como parte de uma circulação intelectual multidirecional no Oceano Índico. Como argumentou Dhupelia-Mesthrie (2006), essa abordagem nos levará para além do atual status quo na história da Índia sul-africana, a qual tende a se concentrar repetidamente em dois temas inerentes às relações África do Sul-Índia, nomeadamente, Gandhi e a luta contra o apartheid. Alguns estudiosos estão começando a se mover além desses temas. Jon Soske (2006) examina as interações entre nacionalismos indianos e africanos no intuito de ultrapassar a existência atual de duas historiografias separadas, uma indiana e outra africana. Paru Raman (2004) também faz um trabalho inovador sobre Yusuf Dadoo e a forma como seu projeto político se desenvolveu entre a África do Sul e a Índia. Ao pensarmos nas zonas de cruzamento entre indianos e africanos, há diversas linhas interessantes a serem exploradas. D.D.T. Jabavu, por exemplo, estava interessado no pacifismo de Gandhi e, em 1949, participou do Encontro Mundial da Paz na Índia, onde ele falou sobre as condições na África do Sul (DHUPELIA-MESTHRIE, 2004, p. 338). Jabavu é uma figura importante no liberalismo negro e, como Dhupelia-Mesthri (2004) mostrou em sua brilhante biografia, Gandhi's Prisoner? The Life of Gandhi's Son Manilal, uma dimensão crítica nessa história seria a não violência e o anticomunismo de Gandhi, uma posição que atraiu uma série de intelectuais, incluindo Jordan Ngubane, 
que escreveu para o jornal Indian Opinion, fundado por Gandhi em 1903 (DHUPELIA-MESTHRIE, 2004, p. 339).

As ilhas seriam fundamentais para a formulação de novos circuitos literários. Há, obviamente, um trabalho substancial sobre as literaturas das várias ilhas do Oceano Índico. No entanto, pouco disso foi pensado com relação à África do Sul. Maurício, por exemplo, tem conjuntos críticos de interações com a África do Sul; All Under Heaven: The Story of a Chinese Family in South Africa (2004), de Darryl Accone, não abrange só Maurício, muito do livro se desenrola no Oceano Índico, abrindo uma nova visão das possibilidades narrativas para a história literária sul-africana.

Parece haver interessantes possibilidades em relação ao pensamento sobre os circuitos literários africanos/holandeses no Oceano Índico. Um rápido exemplo (retirado de uma pesquisa em andamento) pertence a J.L.P. Erasmus, um comandante bôer capturado pelos britânicos em 1903 e enviado (tal qual nove mil outros) como prisioneiro de guerra para a Índia. Durante sua estadia, Erasmus ficou interessado na história e na cultura indianas e, na sua volta à África do Sul, conectou-se com Gandhi e escreveu para o Indian Opinion (HOFMEYR, 2007). Há também uma literatura holandesa mais antiga, do leste da Índia, que forma uma vertente importante na história literária africana e precisa ser mais plenamente considerada na literatura sul-africana.

\section{UNIVERSALISMOS RELIGIOSOS}

De que modo os universalismos religiosos do Oceano Índico podem garantir novos entendimentos da história literária e cultural sul-africana? Visível no trabalho do movimento Arya Samaj, um exemplo é o papel da reforma hinduísta no Oceano Índico, que vem desempenhar um papel central no nacionalismo hindu e nas comunidades indianas, no exterior. Fundado na Índia em 1874, o movimento Arya Samaj, como muitas organizações reformistas hindus, respondeu à investida da evangelização da missão cristã buscando "modernizar" o hinduísmo e constituí-lo como uma organização semelhante à Igreja, com congregações, horários de reuniões fixos e textos predefinidos. Como uma organização revivalista, o Samaj teve tendências evangélicas e, tanto em casa como no exterior, procurou "salvar" os hindus de perderem a sua fé, ou reconverter aqueles que a perderam. O Samaj enviou missionários para diferentes partes da diáspora contratada. 
Há uma tradição de estudos consistente sobre o Samaj, que porém se divide em duas vertentes distintas. Existem diversos estudos sobre o Samaj na Índia (JORDENS, 1997; RAI, 1992) e estudos menores em outros lugares: na África do Sul, Trinidad e África Oriental (VEDALANKAR; SOMERA, [s.d.]; NAIDOO, 1992). Com exceção do trabalho de Kelly (1991) sobre Fiji, não houve nenhuma tentativa de combinar essas duas vertentes de estudo e tratar essas áreas como um espaço integrado que poderia elucidar o modo como os debates do Samaj na periferia alimentam os debates "de volta para casa” na Índia. Muitas vezes, esses debates na Índia diziam respeito aos limites da identidade Hindu e à questão de quem poderia ser hindu. Na periferia constituída pelos contratados, esses debates tiveram muitas vezes contornos dramáticos extremos e, nalguns momentos diziam respeito à questão sobre se um africano poderia ser hindu, ou não. Precisamos de histórias intelectuais e literárias que possam rastrear esses debates na África do Sul, os canais através dos quais os contratados retornam de volta à Îndia e de que forma isso ocorre.

Tal domínio também tornará visível uma série de histórias de vida que se desenrolam entre a África do Sul e a Índia e têm importantes implicações para a literatura sul-africana. Dois exemplos seriam Bhawani Dayal, nascido na África do Sul, e Bhai Parmanand, nascido na Índia. Ambos faziam parte do movimento Arya Samaj e passaram considerável tempo entre a África do Sul e a Índia (e, no caso de Parmanand, noutros países também).

Dayal nasceu em 1892, em Joanesburgo, filho de um contratado. Em 1904, ele retornou à Índia para completar sua escolaridade e participou do movimento swadeshi, uma campanha anticolonial em resposta à partição de Bengala. Ele também se aproximou de Arya Samaj. Dayal retorna para Natal em 1912 e participa da satyagraha/resistência passiva de Gandhi. Ele é preso e produz a sua autobiografia em hindu, Hamari Karavas Kahani (Story of my Prison Life). ${ }^{4}$ Em 1914 ele produz Dakshin Afriakela Satyagrah ka Itihas (History of Passive Resistance in South Africa) sendo o primeiro relato da resistência passiva em Hindu. ${ }^{5}$ Continua a viajar entre a África do Sul e a Índia e se envolve com o Congresso Indiano de Natal, o qual, por muitos anos, ele representa nas reuniões anuais do Congresso Indiano na Índia (AGRAWAL, 1939). Há muito mais por dizer sobre Dayal.

4 Título e tradução, conforme indicado no catálogo da Biblioteca Pública de Joanesburgo. 5 Título e tradução, conforme anotado em Bhawani Dayal Sasnnyasi de Prem Nairan Agrawa (1939, Apêndice I). 
Algumas das implicações que o seu trabalho representa para as definições da literatura sul-africana são indicações de que precisamos começar a pensar nos textos hindus como parte integrante do arquivo literário sul-africano. A autobiografia de Dayal daria uma contribuição interessante para os debates tanto sobre as histórias de vida sul-africanas, quanto sobre a literatura na prisão. De fato, esse parece um excelente projeto de colaboração entre os estudiosos sul-africanos e indianos.

Deixem-me focar brevemente em Parmanand, que nasceu em Punjab. Eleé talvez mais conhecido por ter sido condenadoà morte pelos britânicos em 1915, devido à sua participação em uma suposta conspiração. Sua sentença foi diminuída para prisão perpétua nas ilhas de Andaman e, em 1920, foi libertado no âmbito de uma amnistia geral. Menos conhecido é o fato de que ele passou algum tempo em Pietermaritzburg, em 1905, como representante do Arya Samaj, e que ali fundou a Associação dos Jovens Hindus. Sua autobiografia The Story of My Life (1982) toca brevemente em suas experiências sul-africanas e seria útil incluí-la no arquivo da literatura sul-africana.

O Cristianismo no Oceano Índico também pode produzir narrativas inesperadas. Uma delas seria um relato de John Rungiah, um missionário batista de Telegu que veio do Sul da Índia para doutrinação em Natal em 1903 (RUNGIAH, 1905). Esses movimentos sul-sul terão interessantes implicações para a compreensão da missão cristã, que é quase uniformemente concebida como um fenômeno norte-sul.

O Islamismo garantiu os mais amplos universalismos do Oceano Índico. Até hoje, a ideia do Islamismo e da escrita islâmica praticamente nunca foi levada em conta, de forma consistente, nas histórias literárias e culturais da África do Sul. O desenvolvimento desse projeto ajudaria a alargar os limites e vetores da literatura sul-africana de forma substancial. Um projeto como esse consideraria minimamente os escritores "seculares" que se envolvem com temas islâmicos ou corânicos (pense-se, por exemplo, em Shabbir Banoobhai) e o que isso significaria, uma vez equacionado, para as historiografias da literatura sul-africana. Também seria importante abordar as representações do Islã; um exemplo interessante é Blanket Boy's Moon, de Peter Lanham e A.S. Mopeli-Paulus (1984), que trata em parte de um retrato positivo da comunidade islâmica de Durban na década de 1940. As escritas de praticantes religiosos na África do Sul constituirão um vasto conjunto de trabalho em várias línguas. O recente estudo do Círculo de Estudos Árabes em Durban, de Shamil Jeppie (2007), destaca-se nessa 
área, assinalando os temas que um estudo detalhado de uma comunidade literária particular pode abrir.

Para concluir, deixem-me trazer as seguintes questões até o presente. Que diferença o Oceano Índico faz hoje? Conforme indicado anteriormente, houve uma intensificação significativa do comércio entre a África do Sul e a Índia. Está claro que o futuro da África do Sul será significativamente moldado pela Índia. Este artigo sugere que precisamos urgentemente começar a escrever as histórias desse presente que está surgindo.

Tradução de: Ana Mafalda Leite Jessica Falconi Elena Brugioni

\title{
THE BLACK ATLANTIC MEETS THE INDIAN OCEAN: FORGING NEW PARADIGMS OF TRANSNATIONALISM FOR THE GLOBAL SOUTH. LITERARY AND CULTURAL PERSPECTIVES
}

\begin{abstract}
With the recent transnational turn in the humanities and social sciences, questions of translocalism have come to dominate the academic agenda. Where southern African studies has engaged with transnationalism, this has generally been pursued through the framework of the black Atlantic. This articleargues that we need to supplement this perspective with a systematic engagement with the Indian Ocean. The article outlines various major historiographical traditions associated with the Indian Ocean and then seeks to draw out how these themes challenge assumptions which have been theorised on the basis of black Atlantic patterns. The paper concludes with a discussion of how a consideration of the Indian Ocean would enlarge the maps of South African literary and cultural studies.
\end{abstract}

Keywords: Indian Ocean; Global South; Transnational paradigms.

\section{REFERÊNCIAS}

ACCONE, Darryl. All Under Heaven: The Story of a Chinese Family in South Africa. Cidade do Cabo: David Philip, 2004.

ACHARYA, Gunvantrai. Dariyalal. Trad. Kamal Sanyal. Calcutta: Dictum, 2000 [1974].

AGRAWAL, Prem Nairan. Bhawani Dayal Sannyasi: A Public Worker in South Africa. Ajitmal: Indian Colonial Association, 1939.

ALI, Shanti Sadiq. The African Dispersal in the Deccan: From Medieval to Modern Times. Hyderabad: Orient Longman, 1995. 
ALPERS, Edward A. Gujarat and the Trade of East Africa, c. 1500-180o. International Journal of African Historical Studies, v. 9, n. 1, 1976, pp. 22-44.

ANDERSON, Clare. "The Ferringees are Flying - The Ship is Ours!": The Convict Middle Passage in Colonial South and Southeast Asia, 1790-186o. Indian Economic and Social History Review, v. 42, n. 2, 2005, pp. 143-186.

ANDREWS, Charles Freer. South Africa and India: Olive Schreiner's Message. Modern Review, v. 43, n. 6, jun. 1928, pp. 641-646.

ANON. East Africa Developed by Indians. Modern Review, v. 30, n. 3, set. 1921, pp. 355-356.

ANON. Chhota Imperialists. Modern Review, v. 43, n. 3, mar. 1928a, pp. 356-357.

ANON. Indians Abroad. Modern Review, v. 43, n. 4, abr. 1928b, pp. 491-495.

ANON. Indians Abroad. Modern Review, v. 44, n. 2, ago. 1928c, p. 224.

BALACHANDRAN, Gopalan. Circulation through Seafaring: Indian Seamen, 1890-1945. In: MARKOVITS, Claude; POUCHEPADASS, Jacques; SUBRAHMANYAM, Sanjay (Eds.). Society and Circulation: Mobile People and Itinerant Cultures in South Asia 1750-1950. Deli: Permanent Black, 2003, pp. 89-130.

BAYART, Jean-Francois. The State in Africa: The Politics of the Belly. Londres: Longman, 1993.

BHANA, Surendra; BRAIN, Joy. Setting Down Roots: Indian Migrants in South Africa, 1860-1911. Jonesboro: Wits University Press, 1990.

BOSE, Sugata. A Hundred Horizons: The Indian Ocean in an Age of Global Imperialism. Cambridge, Mass.: Harvard University Press, 2005.

BREVILLE, Tristan. Ent Route to India. In: LÉON, Pascal Martin Saint; FALL, N'Goné (Eds.). Anthology of African and Indian Ocean Photography. Paris: Revue Noir, 1999, pp. 399-425.

BULPIN, Thomas Victor. n.d. Islands in a Forgotten Sea. [S.l.]: Howard Timmins, [s.d.].

CAMPBELL, Gwyn (Ed.). Slavery and Other forms of Unfree Labour in the Indian Ocean World. In Gwyn Campbell (Introduction). The Structure of Slavery in Indian Ocean Africa and Asia. Londres: Frank Cass, 2004a, pp. vii-xxxii.

CAMPBELL, Gwyn (Ed.). The Structure of Slavery in Indian Ocean Africa and Asia. Londres: Frank Cass, 2004b.

CAMPBELL, James T. Songs of Zion: The African Methodist Episcopal Church in the United States and South Africa. Nova York: Oxford University Press, 1995. 
CARTER, Marina. Voices from Indenture: Experiences of Indian Migrants in the British Empire. Leicester: Leicester University Press, 1996.

CARTER, Marina; TORABULLY, Khal. Coolitude: An Anthology of the Indian Labour Diaspora. Londres: Anthem Press, 2002.

CHABAL, Patrick; DALOZ, Jean-Pascal. Africa Works: Disorder as Political Instrument. Oxford: James Currey, 1999.

CHATURVEDI, Benarsidas; DAYAL, Bhawani. A Report on the Emigrants Repatriated to India under the Assisted Emigration Scheme from South Africa and on the Problem of Returned Emigrants from all Colonies. 1931. (Mimeo.)

CHETTY, Rajendra (Ed.). South African Indian Writings in English. Durban: Madiba, 2002.

CHRISMAN, Laura. Postcolonial Contraventions: Cultural Readings of Race, Imperialism and Transnationalism. Manchester: Manchester University Press, 2003.

CHRISMAN, Laura. Beyond Black Atlantic and Postcolonial Studies: The South African Differences of Sol Plaatje and Peter Abrahams. In: LOOMBA, Ania et al. (Eds.). Postcolonial Studies and Beyond. Nova Deli: Permanent Black, 2005, pp. 252-271.

COUTO, Mia. How Ascolino do Perpétuo Socorro Lost his Spouse. In: Vozes Anoitecidas. Trad. David Brookshaw. Londres: Heinemann, 1986, pp. 29-41.

COUZENS, Tim. Moralizing Leisure Time: The Transatlantic Connection and Black Johannesburg. 1918-1936. In: MARKS, Shula; RATHBONE, Richard (Eds.). Industrialisation and Social Change in South Africa: African Class Formation, Culture, and Consciousness, 1870-1930. Londres: Longman, 1982, pp. 314-337.

DAS GUPTA, Ashin. India and the Indian Ocean World: Trade and Politics. 2 vols.: Malabar in Asian Trade 1740-180o e Indian Merchants and the Decline of Surat C. 1700-1750. Nova Deli: Oxford University Press, 2004 [1967; 1979].

DHUPELIA-MESTHRIE, Uma. Gandhi's Prisoner? The Life of Gandhi's Son Manilal. Cidade do Cabo: Kwela, 2004.

DHUPELIA-MESTHRIE, Uma. The Place of India in South African History: Academic Scholarship, Past, Present and Future [Conferência]. "South Africa-India: Reimagining the Disciplines: University of the Witwatersrand, Joanesburgo, maio 2006, pp. 19-21.

DRIVER, Dorothy. Drum Magazine (1951-1959) and the Spatial Configurations of Gender. In: NEWELL, Stephanie (Ed.). Readings in African Popular Fiction. Londres/ Bloomington: International African Institute/James Currey/Indiana University Press, 2001, pp. 156-170. 
EISENLOHR, Patrick. Little India: Diaspora, Time and Ethnolinguistic Belonging in Hindu Mauritius. Berkeley: University of California Press, 2006.

EWALD, Janet J. Crossers of the Sea: Slaves, Freedmen, and Other Migrants in the Northwestern Indian Ocean, c.1750-1914. American Historical Review, v. 105, 2000, pp. 69-92.

FAINMAN-FRENKEL, Ronit. Ordinary Secrets and the Bounds of Memory: Traversing the Truth and Reconciliation Commission in Farida Karodia's Other Secrets and Beverley Naidoo's Out of Bounds. Research in African Literatures, v. 35, n. 4, 2004, pp. 52-65.

FATTAH, Hala. Islamic Universalism and the Construction of Regional Identity in Turnof-the-Century Basra: Sheikh Ibrahim al-Haidari's Book Revisited. In: FAWAZ, Leila; BAYLY, Christopher Alan. (Eds.). Modernity and Culture: From the Mediterranean to the Indian Ocean. Nova York: Columbia University Press, 2002, pp. 112-129.

FAWAZ, Leila Tarazi; BAYLY, Christopher Alan (Eds.). Modernity and Culture: From the Mediterranean to the Indian Ocean. Nova York: Columbia University Press, 2002.

FROST, Mark Ravinder. “Wider Opportunities”: Religious Revival, Nationalist Awakening and the Global Dimension in Colombo, 1870-1920. Modern Asian Studies, v. 36, n. 4, 2002, pp. 937-967.

GANDHI, Mohandas Karamchand Indians Abroad. Young India, 17 December. In: Collected Works of Mahatma Gandhi. V. 19, 1919, pp. 184-186. Disponível em: <http:// www.gandhiserve.org/cwmg/cwmg.html>.

GHOSH, Amitav. In an Antique Land: History in the Guise of a Traveller's Tale. Londres: Vintage, 1992.

GILROY, Paul. The Black Atlantic: Modernity and Double Consciousness. Londres: Verso, 1993.

GLASSMAN, Jonathan. Feasts and Riot: Revelry, Rebellion, and Popular Consciousness on the Swahili Coast, 1856-1888. Londres: James Currey, 1994.

GOVINDEN, Devarakshanam. In: Sister Outsider: The Representation of identity and Difference in Selected Writings by South African Indian Women. Pretoria: Unisa Press, 2008.

GREGORY, Robert G. India and East Africa: A History of Race Relations within the British Empire. 1890-1939. Oxford: Clarendon Press, 1971.

GUPTA, Pamila. Mapping Portuguese Decolonisation: From Goa to Maputo and Beyond. Trabalho apresentado no "South Africa-India: Re-imagining the Disciplines". University of the Witwatersrand, Joanesburgo, maio 2006, pp. 19-21.

GURNAH, Abdulrazak. Paradise. Nova York: New Press, 1994. 
HALL, Richard. Empires of the Monsoon: A History of the Indian Ocean and its Invaders. Londres: Harpercollins, 1996.

HERGÉ. The Adventures of Tintin: The Red Sea Sharks. Trad. Leslie Lonsdale- Cooper and Michael Turner. Londres: Egmont, 1960.

HO, Engseng. The Graves of Tarim: Genealogy and Mobility across the Indian Ocean. Berkeley: University of California Press, 2006.

HOFMEYR, Isabel. The Idea of "Africa" in Indian Nationalism: Reporting the Diaspora in The Modern Review. Artigo apresentado no "South Africa- India: Re-imagining the Disciplines”. University of the Witwatersrand, Joanesburgo, maio 2006, pp. 19-21.

HOFMEYR, Isabel. Indian Ocean Lives and Letters: Nova Textual Circuits, Nova Book Histories. Keynote address. "A World Elsewhere: Orality, Manuscript and Print in Colonial and Postcolonial-Cultures". Cidade do Cabo, Centre for the Book, abr. 2007, pp. 2-4.

HYSLOP, Jonathan. How the British Working Class became White: The Symbolic (Re) formation of Racialized Capitalism. Journal of Historical Sociology, v. 11, n. 3, 1999, pp. 316-340.

JAMES, Cyril Lionel Robert. From Toussaint L'Ouverture to Fidel Castro. In: GRIMSHAW, Ann (Ed.). The C.L.R. James Reader. Oxford: Blackwell, 1992 [1962], pp. 296-314.

JAYASURIYA, Shihan de S.; PANKHURST, Richard. On the African Diaspora in the Indian Ocean. In: JAYASURIYA, Shihan de S.; PANKHURST, Richard (Eds.). The African Diaspora in the Indian Ocean. Trenton: Africa World Press, 2003, pp. 1-17.

JEPPIE, Shamil. Language, Identity, Modernity: The Arabic Study Circle of Durban. Cidade do Cabo: Human Sciences Research Council Press, 2007.

JORDENS, Joseph Teresa Florent. Dayananda Sarasvati: His Life and Ideas. Deli: Oxford University Press, 1997.

KEARNEY, Milo. The Indian Ocean in World History. Londres: Routledge, 2004.

KELLY, John. A Politics of Virtue: Hinduism, Sexuality and Countercolonial Discourse in Fiji. Chicago: University of Chicago Press, 1991.

KHURSAND, Khushal Chandra. Introduction. In: PARMANAND, Bhai. The Story of My Life. Nova Deli: S. Chand, 1982, pp. xi-xxiii.

KLAAREN, Jonathan. Migrating to Citizenship: Mobility, Law, and Nationality in South Africa, 1897-1937. Tese (PhD) - Yale University. Nova Haven, 2004.

LANHAM, Peter; MOPELI-PAULUS, Atwell Sidwell. Blanket Boy's Moon. Joanesburgo: David Philip, 1984 [1953]. 
LINEBAUG, Peter; REDIKER, Marcus. The Many-Headed Hydra: Sailors, Slaves, Commoners, and the Hidden History of the Revolutionary Atlantic. Londres: Verso, 2000 .

MASILELA, Ntongela. The "Black Atlantic" and African Modernity in South Africa. Research in African Literatures, v. 27, n. 4, 1996, pp. 88-96.

MBEMBE, Achille. On the Postcolony. Trad. A.M. Berrett, Janet Roitman, Murray Last e Steven Rendall. Berkeley: University of California Press, 2001.

MCPHERSON, Kenneth. The Indian Ocean: A History of People and the Sea. Deli: Oxford University Press, 1993.

MESTHRIE, Uma. Reducing the Indian Population to a "Manageable Compass": A Study of the South African Assisted Emigration Scheme of 1927. Natalia, v. 15, 1985, pp. 36-56.

MPHAHLELE, Ezekiel. The African Image. Londres: Faber \& Faber, 1974[1967].

NAIDOO, Thillayvel. The Arya Samaj Movement in South Africa. Deli: Motilal Banarsidass, 1992.

NIRANJANA, Tejaswini. Left to the Imagination: Indian Nationalism and Female Sexuality in Trinidad. Public Culture, v. 11, n. 1, 1999, pp. 223-243.

NIXON, Rob. Homelands, Harlem and Hollywood: South African Culture and the World Beyond. Nova York: Routledge, 1994.

NORTHRUP, David. Indentured Labor in the Age of Imperialism: 1834-1922. Cambridge: Cambridge University Press, 1995.

OJWANG, Dan Odhiambo. Writing Migrancy and Ethnicity: The Politics of Identity in East African Indian Literature. Tese (PhD) - University of the Witwatersrand. Joanesburgo, 2004.

PARMANAND, Bhai. The Story of my Life. Nova Deli: S. Chand, 1982 [1934].

PATHER, S.R. Centenary of Indians, 1860-196o. Durban: Cavalier, 1960.

PEARSON, Michael N. The Indian Ocean. Londres: Routledge, 2003.

PETERSON, Bhekizizwe. Monarchs, Missionaries and African Intellectuals: African Theatre and the Unm aking of Colonial Marginality. Joanesburgo: Wits University Press, 2000.

PINTO, Rochelle. Race and Imperial Loss: Accounts of East Africa in Goa. Artigo apresentado no "South Africa-India: Re-imagining the Disciplines". University of the Witwatersrand. Joanesburgo, maio 2006, pp. 19-21. 
RAI, Lajpat. A History of the Arya Samaj: An Account of its Origin, Doctrines and Activities with a Biograph Ical Sketch of the Founder. Nova Deli: Munshiram Manoharlal, $1992[1915]$.

RAMAN, Parvathi. Yusuf Dadoo: Transnational Politics, South African Belonging. South African Historical Journal, v. 50, 2004, pp. 27-48.

RAMASWAMY, Sumathi. Catastrophic Cartographies: Mapping the Lost Continent of Lemuria. Representations, v. 67, 1999, pp. 92-129.

RAMASWAMY, Sumathi. History at Land's End: Lemuria in Tamil Spatial Fables. Journal of Asian Studies, v. 59, n. 3, 2002, pp. 575-602.

RAY, Rajat Kanta. Asian Capital in the Age of European Domination: The Rise of the Bazaar, 1800-1914. Modern Asian Studies, v. 29, n. 3, 1995, pp. 449-554.

REDIKER, Marcus. Between the Devil and Deep Blue Sea: Merchant Seamen, Pirates and the Anglo-American Maritime World, 1700-1750. Cambridge: Cambridge University Press, 1987.

RISSO, Patricia. Merchants and Faith: Muslim Commerce and Culture in the Indian Ocean. Boulder: Westview Press, 1995.

RUNGIAH, John. The First and Second Annual Reports of the Telegu Baptist Mission, Natal, South Africa, 1903-1905. Madras: M.E. Press, 1905.

SEGAL, Ronald. Islam's Black Slaves: A History of Africa's Other Black Diaspora. Londres: Atlantic Books, 2001.

SOSKE, Jon. The Indian Diaspora and African Nationalism in South Africa, 1946-1976. Artigo apresentado no "South Africa-India: Re-imagining the Disciplines". University of the Witwatersrand, Joanesburgo, maio 2006, pp. 19-21.

TADVALKAR, G.B. Indians in British East Africa. Modern Review, v. 25, n. 2, fev. 1919, pp. 109-115.

TINKER, Hugh. A New System of Slavery: The Export of Indian Labour Overseas, 18301921. Londres: Oxford University Press, 1974.

TITLESTAD, Michael. Making the Changes: Jazz in South African Literature and Reportage. Pretoria: Unisa Press, 2004.

TOUSSAINT, Auguste. History of the Indian Ocean. Trad. June Guicharnaud. Londres: Routledge and Kegan Paul, 1966.

VAN DER VEER, Peter. Imperial Encounters: Religion and Modernity in India and Britain. Deli: Permanent Black, 2001. 
Remate de Males, Campinas-SP, v. 38, n. 1, pp. 10-41, jan./jun. 2018 - 41

VEDALANKAR, Nardev; SOMERA, Manohar. Arya Samaj and Indians Abroad. Durban: Sarvadeshik Arya Pratinidhi Sabha, [s.d.].

VERGÈS, Françoise. Writing on Water: Peripheries, Flows, Capital, and Struggles in the Indian Ocean. Positions: East Asia Cultures Critique, v. 11, n. 1, 2003, pp. 241-257.

VISWANATHAN, Gauri. Outside the Fold: Conversion, Modernity, and Belief Princeton: Princeton University Press, 1998. 